\title{
As Origens do Método de Rorschach e seus Fundamentos
}

The origins of the Rorschach and its foundations

Marta Helena de

Freitas

Universidade

Católica de Brasília 


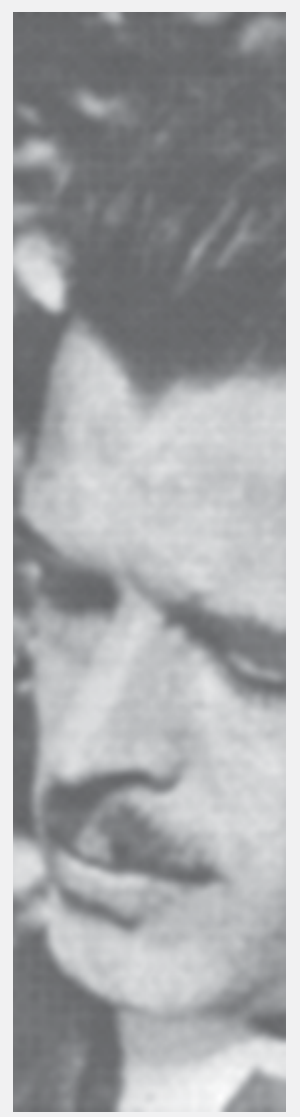

Resumo: As origens do método de Rorschach e seus respectivos fundamentos são temas deste trabalho, desenvolvido a partir de uma retomada fenomenológica da história pessoal e profissional de seu próprio inventor, passando pela descrição e análise das principais influências e bases teóricas do referido método e, finalmente, culminando com uma apreciação acerca da subjacente concepção de personalidade, mais propriamente dada pelos conceitos de tipo de vivência e função do real, em suas acepções originais.

Palavras-chave: método de Rorschach, história da Psicologia, psicodiagnóstico, Hermann Rorschach.

Abstract: The theme of this work is the origin and the foundations of the Rorschach method. The work was developed from a phenomenological review of the personal and professional history of its own inventor, which involves a description and analysis of the main influences and theoretical basis of the referred method. Finally, this work culminates in an appreciation of the underlying conception of personality, more specifically those provided by the concepts of a type of experience and function of the real in their original meanings.

Key words: Rorschach method, history of Psychology, psychodiagnostic, Hermann Rorschach.
Atualmente, encontra-se uma bibliografia extremamente vasta acerca do método de Rorschach - são milhares de trabalhos publicados, centenas de grupos e associações científicas que se dedicam a seu estudo e uma enorme quantidade de revistas especializadas. Sem dúvida que os trabalhos que se seguiram à genial criação do método contribuíram e têm contribuído para seu respectivo aprofundamento e aperfeiçoamento, seja em termos da técnica de aplicação, seja em termos da apreciação de seus resultados. Entretanto, conforme bem já o apontava Miralles (I967) ao prefaciar a versão espanhola da obra
Herman Rorschach: Obras Menores e Inéditas, recopiladas por Bash (1964/1967), há de se reconhecer também que toda essa extraordinária difusão da prova, acompanhada das discussões em torno de seus diversos aspectos psicológicos e diagnósticos bem como de sua validade em geral, como procedimento científico ou como técnica projetiva, tem contribuído muito mais para ocultar a própria gênese do método e as relações desta com a personalidade do seu próprio criador. Se isso já se constatava na década de 60, hoje quer parecer-nos que esse fenômeno de ocultamento tem-se acentuado ainda mais,
"Toda sensitividade traz o cunho de mentalidade."

Suzanne $K$. Langer 
em especial por conta das preocupações normativas, indexiais e pragmáticas que têm caracterizado o emprego do método no contexto clínico, organizacional, jurídico ou de pesquisa e as respectivas implicações éticas daí decorrentes.

Conforme acentuou Ellenberger (1954/ 1967), a morte prematura de Rorschach, arrebatando-o apenas nove meses após a publicação de seu Psicodiagnóstico, impediu-o de continuar apresentando e desenvolvendo seus descobrimentos, que, naquela época, tomavam já uma nova direção e abrigavam grandes esperanças em novos e extraordinários rendimentos científicos. Além disso, as difíceis circunstâncias nas quais se deu a emergência da referida obra (que são suficientemente descritas no artigo necrológico de Morgenthaler, 1954/1967), acabou levandoo a ser de leitura e compreensão bastante difíceis, mais ainda por conter uma exposição bastante incompleta dos respectivos fundamentos do método. Essa incompletude acabou favorecendo uma evolução posterior quase independente do mesmo, após a morte de seu criador, e promovendo uma distância cada vez maior na conexão entre as idéias originais de Rorschach e o método que levou seu próprio nome. Assim, muitos ignoram, por exemplo, que Rorschach, além de inventar o referido método, foi também um profundo pensador e investigador da natureza humana. Convencido de que uma consideração profunda acerca da significação original do Psicodiagnóstico poderia promover o descobrimento de novas possibilidades do teste e render frutos em diversos setores da Psicologia, Ellenberger (1954/1967) propôsse à difícil tarefa de esclarecer seu significado original a partir de uma tripla investigação, dedicada à vida, à personalidade e às idéias de Hermann Rorschach. É, principalmente, a partir desse texto, algumas vezes complementando-o com outra contribuição encontrada também na obra organizada por Bash (19541967), que se desenvolverá, a seguir, um exercício de maior estreitamento das conexões entre o inventor e sua invenção. Entendemos ser de grande importância o resgate dessa gênese bem como dos pressupostos que estariam na base do método, em especial no cenário atual de intensas discussões em torno dos instrumentos de diagnósticos em Psicologia e respectivas normatizações.

\section{Antecedentes históricos}

A origem do Psychodiagnostik (Rorschach, 1921/1974) - título original ${ }^{1}$ da obra publicada pela primeira vez em 1921, constitui, até os dias de hoje, um grande enigma, e, segundo o biógrafo Ellenberger (1954/1967), já o era também para alguns contemporâneos de seu próprio criador, levando Kuhn a caracterizá-la como um verdadeiro monolito erguido entre a literatura psiquiátrica da época.

Vários autores citam que o primeiro emprego das manchas de tinta, como material psicológico, teria sido descrito num livro intitulado Kleksographien, publicado em 1857, em Tubinga, Alemanha, de autoria do psiquiatra Justinus Kerner, ao qual Ellenberger se refere como aquele extravagante médico alemão e poeta romântico, mas que, no dizer de Klopfer e Kelly (1942/1974), poderia ser considerado, sob muitos aspectos, o percursor da psiquiatria moderna. Kerner teria descoberto as possibilidades encerradas no emprego das manchas de tinta de forma acidental e, ao observá-las, teria notado como elas assumiam diversas formas, que o impressionavam por seus raros significados. 
Então, logo começou a produzi-las deliberadamente, abrindo sua investigação e experimentação a um caminho novo que incendiou a imaginação pública, provocando uma verdadeira mania pelas manchas. "A mais interessante observação de Kerner", afirmam os referidos autores, "foi que the pareceu impossível produzir manchas de tinta seguindo-se um plano preconcebido, pois as manchas de tinta tendiam a impor seu sentido e significado ao produtor" (p. 23). O excêntrico psiquiatra teria, então, experimentado "o poderoso jogo recíproco entre os traços objetivos das manchas de tinta e as projeções pessoais do observador, que, ainda hoje, constitui, para todos, a mais forte experiência no primeiro encontro com o material do Rorschach" (p. 23). Ainda segundo Klopfer e Kelly (1942/1974), Kerner não teria chegado "a compreender por completo que esse jogo recíproco produzia resultados diferentes em pessoas distintas, nem tampouco a reconhecer a significação de tais diferenças como fundamento para um método de diagnóstico da personalidade" (p. 23).

Curiosamente, em sua respectiva biografia, levada a termo por Seeber (1975/1999), além de poeta romântico, Justinus Kerner é descrito como tendo sido "médico e pesquisador do lado obscuro da natureza" (p. 5) e um verdadeiro "feiticeiro da personalidade" (p. 7). Ligado à corrente então muito propagada em seu meio, qual seja, a da "força curadora do 'magnetismo animal'" (p. 6), Kerner chegou a publicar uma obra clássica de ocultismo e parapsicologia intitulada Die Seherin von Prevorst (A Vidente de Prevorst), relacionando aparições que se situariam para além "da experiência perceptível pela inteligência e pelos sentidos" (p. 6). Segundo o referido biógrafo, os borrões de tinta eram um dos hobbies de Kerner na velhice, e "manchavam, por vezes, as cartas e manuscritos do quase cego poeta" (p. 4). Assim, obtinha maravilhosos quadros e imagens, verdadeiros demônios, com os quais, em versos esclarecedores, ele se divertia $^{2}$.

Também Jung (1981/1998), em suas conferências sobre os fenômenos espíritas, refere-se às experiências de Justinus Kerner, que teria escrito um tratado sobre o contato com o mundo dos espíritos, por meio de movimentos automáticos de mesa, sob o sugestivo título alemão: Die Somnambülen Tische. Zur Geschichte und Erklärung dieser Erscheinungen, em 1853.

Conforme apontado por Ellenberger (1954/ 1967), milhares de crianças suíças teriam brincado com as kleksografias, dentre elas também o próprio Rorschach, mas este não se teria se limitado a realizar borrões ou a contemplar aqueles feitos por outras pessoas. Teria, sim, demonstrado sua originalidade ao procurar examinar as reações de crianças e de adultos perante as manchas de tinta e ao compará-las umas com as outras, com bases em tais reações.

De qualquer modo, entre aquele primeiro emprego das manchas de tinta, realizados experimentalmente por Justinus Kerner, e a emergência do Psicodiagnóstico, em 1921, outras tentativas ocorreram, no emprego do método, para fins de estudos psicológicos. Assim, Binet (conforme citado por Klopfer \& Kelly, 1942/1974) e Simon (conforme citado por Anzieu, 1961/1979), em 1895, e, mais tarde, em 1910, Whipple (conforme citado por Klopfer \& Kelly, 1942/1974), teriam sugerido o uso das manchas de tinta para o estudo de diversos traços de personalidade. Este último chegara a publicar, pela primeira vez, uma série padronizada das manchas de tinta, a partir
Conforme apontado por Ellenberger (1954) 1967), milhares de crianças suíças teriam brincado com as kleksografias, dentre elas também o próprio Rorschach, mas este não se teria se limitado a realizar borrões ou a contemplar aqueles feitos por outras pessoas.
2 Uma compilação das assim chamadas klecksografias é, ainda hoje, conservada em manuscrito no Museu Nacional Schiller, em Marback. 
do que se teria seguido uma série de estudos concernentes ao assunto, todos eles tendo como parâmetro aquilo que o sujeito via, ao observar as manchas, considerando-as como uma prova de imaginação. Ainda em 1910, segundo Anzieu (1961/1979), o psicólogo russo Rybakoff teria publicado um Atlas de oito manchas, com as quais avaliava a força, a riqueza e a acuidade da imaginação. Também Bartlett (conforme citado por Anzieu, 1961/1979), na Inglaterra, em 1916, teria sido o primeiro a introduzir as cores na técnica das manchas. Tudo indica, entretanto, que Rorschach não tinha ainda ouvido falar em seus antecessores quando começou a realizar suas primeiras pesquisas, as quais resultaram, posteriormente, no seu Psicodiagnóstico.

Comenta Anzieu (1961/1979) que chega a ser extraordinário saber, por exemplo, que, em sua juventude, Rorschach teria recebido dos colegas o apelido de Klex, que significa, justamente, mancha de tinta, borrão. Não se sabe se o apelido teria vindo em alusão aos rabiscos do pai, que era pintor, ou ao gosto do filho pelo desenho - Rorschach tinha dons artísticos - ou se pelo seu gosto especial pela Klecksographie. O fato é que, mais tarde, como médico psiquiatra, ele é reencontrado, nos hospitais, apresentando manchas de tinta para seus pacientes - agora procedendo com espírito clínico e científico - e comparando as respostas destes com as de pessoas normais.

Se, de um lado, os antecedentes mencionados anteriormente ajudam a compreender, pelo menos em parte, o enigma do método de Rorschach, por outro lado, é também verdade que não tira o mérito de sua originalidade, pois o seu Psychodiagnostik apresentou completa mudança de acentuação, que deixou de ser sobre o conteúdo mais ou menos imaginativo das respostas do sujeito para se dar sobre certas características formais das produções conceituais.

O seu interesse, portanto, não se apoiou tanto no que o sujeito via, mas muito mais na maneira com que ele manuseava o material de estimulação. O jogo recíproco entre as características estruturais do material estimulante e a estrutura de personalidade do sujeito reflete-se em certas categorias formais, que descrevem as características das formações conceituais e que são estabelecidas pelo Psychodiagnostik como fundamento de um método para o diagnóstico da personalidade (Klopfer \& Kelly, 1942/1974).

\section{O inventor e sua invenção}

Hermann Rorschach nasceu em Zurich, em 8 de novembro de 1884 , tendo sua infância sido transcorrida em Schaffhausen. Era o filho mais velho de um pintor e professor de desenho, que veio a falecer em 1903, época em que Rorschach encerrava seus estudos na escola secundária de Schaffhouse e onde o pai ensinava desde 1886. Muito bem dotado para o desenho, por um tempo, hesitou entre a carreira artística e a carreira médica. Acabou optando pela segunda, com a ajuda do grande biólogo Haeckel. Estudou Medicina em diversas universidades, como de hábito naquela ocasião, mas a maior parte de sua carreira deu-se em Zurich, e logo passou a ser médico assistente nas clínicas de Münsterlingen, Münsingen e Waldau.

Durante sua formação em Medicina, Rorschach teria encontrado, no ambiente universitário, uma autêntica revolução psiquiátrica, e, certamente, se entusiasmado bastante com ela. As idéias de Freud, após 
dez anos rechaçadas e/ou ignoradas, agora passavam a ocupar o primeiro plano de interesse entre vários psiquiatras. O inconsciente já não era mais considerado mera abstração filosófica, mas, sim, poderosa energia que se manifestava sob a forma de sonhos, atos falhos, chistes e crises de histeria, fenômenos obsessivos e estados de angústia. Também Jung havia descoberto um método para descobrir representações inconscientes, por meio da prova de associação de palavras, e, junto com Bleuler, introduziu a interessante novidade de aplicar os conhecimentos psicanalíticos e a referida prova nas investigações da psicose (e não apenas das neuroses, como, inicialmente, havia feito Freud). Conforme ressalta Ellenberger (1954/ 1967, p. 31), embora as premissas teóricas que orientavam tais métodos fossem ainda praticamente inaceitáveis naquela época "de uma psiquiatria materialista e de orientação exclusivamente organicista", elas permitiam decifrar "as aparentemente 'absurdas', 'incompreensíveis' e 'insensatas' idéias dos pacientes psicóticos".

Mais tarde, na Rússia, país pelo qual nutria profunda admiração e interesse especial, Rorschach fez várias amizades interessantes, destacando-se a que travou com Eugen Minkowski (aproximadamente em 1910). Por volta de 1911, teve como mestre Konrad Gehring, com quem passou a colaborar no trabalho exploratório, com os próprios alunos, de aplicação das manchas de tinta, formadas por borrões na folha dobrada. Rorschach discutia com o mestre os resultados das experiências, nas quais procuravam observar se os alunos mais desenvolvidos possuíam mais fantasias do que os menos desenvolvidos intelectualmente, mas acabou abandonando tais experimentos para dedicar-se cada vez mais à psicanálise.
De fato, entre 1909 e 1913, em Zurich, constituía-se um grupo psicanalítico, ao qual pertenciam: Eugen Bleuler, C. G. Jung, Alphons Maeder, Ludwig Binswanger, Oskar Pfister, dentre outros. Rorschach aderiu ao grupo, publicando em seguida, numa das primeiras revistas psicanalíticas da época (Zentralblatt für Psychoanalyse), algumas referências, notas e críticas. Em alguns desses trabalhos, utilizava como método auxiliar o teste de associações de palavras, de Jung.

Durante o período em que esteve em Münsingen, no ano de 1913, Rorschach tomou conhecimento de algumas seitas bastante curiosas e, mais especialmente, do fundador de uma delas, conhecido como Binggeli, ao qual dedicou um estudo bastante detalhado, chegando a visitá-lo em seu povoado. Voltando à Suíça, mais tarde, continuou seus estudos acerca do assunto. Informa Ellenberger (1954/1967) que Rorschach estava convencido de que o estudo acerca das seitas suíças haveria de constituirse a obra máxima de sua vida. Seus estudos sobre o assunto foram reconhecidamente ricos e interessantes, permitindo-lhe traçar um quadro geral das seitas religiosas suíças e resultando numa excelente síntese de Psicologia religiosa, Sociologia, psicopatologia e psicanálise.

Em 1919, com a criação de um novo grupo psicanalítico, seu amigo Emil Oberholzer é nomeado presidente e convida-o para assumir a vice-presidência. As primeiras sessões do grupo foram dedicadas à psicopatologia da religião e, nelas, Rorschach apresentou os casos Bingelli e Unternährer, este último também famoso fundador de uma seita. Rorschach encontrou, nesse grupo, uma atmosfera muita mais aberta do que na Sociedade Suíça de Psiquiatria, e suas idéias foram acolhidas com muito mais interesse.
Durante o período em que esteve em Münsingen, no ano de 1913, Rorschach tomou conhecimento de algumas seitas bastante curiosas e, mais especialmente, do fundador de uma delas, conhecido como Binggeli, ao qual dedicou um estudo bastante detalhado, chegando a visitálo em seu povoado. 
Conforme se constata nas correspondências trocadas com Morgenthaler (1954/1967), referidas no artigo necrológico mencionado anteriormente, Rorschach mantinha uma atitude bastante crítica em relação à tendência fechada de alguns grupos psicanalistas, e propunha-se a formar, junto com outros colegas, uma espécie de grupo de frente de oposição àqueles, sob pena de transformar-se a psicanálise numa espécie de catecismo pleno de dogmas. Assim, insistia em convidar o amigo, que se mostrava resistente a entrar numa sociedade psicanalítica, a fazer parte desse grupo, justamente por criticar as posições exclusivistas perante as questões de Psicologia e psicopatologia, apresentando os seguintes argumentos: "precisamente aqueles médicos que conhecem a fundo outros métodos e que sentem sobre eles o devido respeito científico haveriam de ser encarregados de 'educar' a psicanálise" (p. 103). Rorschach entendia que a psicanálise estava repleta de conceitos alijados da fisiologia, que o tempo haveria de aclarar e fixar: argumentava que isso não se daria mediante congressos ou através da literatura, "pois aí cada qual fala seu próprio idioma e os conceitos levam mais uma existência espectral" (p.103). Mas, uma sociedade que se reunisse pelo menos uma vez por mês talvez fosse capaz de fazer algo a respeito. Tal atitude crítica de Rorschach com relação a alguns aspectos da psicanálise confirmase em depoimento, oferecido por sua esposa, Olga Rorschach (1943/1967), também num artigo necrológico ${ }^{3}$, publicado na mesma obra organizada por Bash. Nesse depoimento, ela acentua que Rorschach não aceitava todas as afirmações de Freud, considerando a psicanálise "tão somente como um método terapêutico com indicações precisas" e "opondo-se decididamente à tendência então dominante de aplicá-la a todas as questões da vida e inclusive à literatura", pois "via nisso um risco de castração do espírito humano, de nivelação, de supressão da bipolaridade, essa premissa necessária a toda dinâmica" ( p. 95).

Até 1917, Rorschach trabalhava animadamente com o firme propósito de escrever uma obra baseada na vasta documentação recopilada acerca das seitas suíças. Entretanto, após tomar conhecimento do trabalho de investigação do jovem Szymons Hens, que havia estudado em Zurich durante os anos de 1912 a 1917 e trabalhado um certo tempo em sua policlínica médica, renunciou de pronto àqueles propósitos e começou a trabalhar com muito entusiasmo e zelo em seu teste de manchas de tinta. Afirma Ellenberger (1954/1967) que o trabalho de Hens teria recordado a Rorschach os seus experimentos anteriores, fazendo com que as idéias daquela época, mantidas mais ou menos inconscientes até então, se fizessem, agora, plenamente claras. $\mathrm{Na}$ verdade, Rorschach viu-se menos inspirado pelos resultados apresentados por Hens do que pelas perguntas que ficaram em aberto, dentre elas:

Certos sujeitos interpretam toda a mancha de tinta e outros somente detalhes - esse fato terá algum significado? Todas as manchas eram em preto e branco - que resultados seriam obtidos com manchas coloridas? Esse método serviria para o diagnóstico das psicoses? (Anzieu, 1961/1979, p. 48).

A partir daquele momento, então, Rorschach passou a dedicar-se intensamente ao novo trabalho. Num curto espaço de tempo - um pouco mais de três anos - e, ainda, paralelamente a todas as demais funções na Sociedade Psicanalítica, ao seu trabalho acerca das seitas suíças e, ainda, como chefe 
clínico do hospital, trabalhou na elaboração das lâminas, nas suas respectivas aplicações a pacientes e a pessoas normais e redigiu o livro, além de preparar e acompanhar a sua difícil publicação, concluída finalmente em 1921.

A obra surgiu, portanto, longe das universidades, dos laboratórios e das bibliotecas, em uma pequena clínica de neuropsiquiatria. Segundo seu biógrafo, isso explicaria, pelo menos em parte, o chamado enigma de Rorschach, certamente exagerado devido à crença preconceituosa dos europeus de que não seria possível nenhum trabalho científico fora da Universidade. Apesar de jamais ter sido médico assistente em Borghölzli, como muitos de seus colegas à época, Rorschach mantinha relações com vários cientistas: conhecia Bleuler, Monakow, Jung, Ludwig Binswanger, Eugen Minkowski, o grupo psicanalítico suíço, diversos filósofos e teólogos, inclusive da Rússia. "Seu espírito vivo e desperto", afirma Ellenberger (1954/ 1967), "logrou inúmeros estímulos a partir das conversas com tais homens, assim como o diálogo com outros menos eminentes, porém doutos e com personalidade própria, como era, por exemplo, Fankhauser" (p. 49). Além disso, Rorschach conhecia muito bem a literatura psiquiátrica e psicanalítica da época, possuindo grandes conhecimentos também em outros setores - Arte, Etnografia, história das religiões e da literatura russa, dentre outros. Tudo isso, certamente, o equipava para a sua genial criação.

Partindo do princípio de que "nada existe de mais enigmático para a própria personalidade criadora do que o processo de criação", já que, "enquanto a consciência se acha ocupada com certos problemas, o inconsciente pode seguir seus próprios caminhos, caracterizados por inspirações súbitas, sonhos, ou pelo efeito catalizador de uma feliz casualidade que constele e plasme o que vinha formando-se no inconsciente" (p. 50), Ellenberger (1954/1967) entende que, enquanto Rorschach se ocupava com afã do mecanismo de alucinações reflexas (tema de seu doutorado), da psicanálise e da sociopsicopatologia das seitas suíças, "seu insconsciente se ocupava de outros temas que constantemente afloravam para voltar a abandoná-los temporariamente, até que se sedimentaram por último no Psicodiagnóstico" (p.50). Propõe-se, portanto, a explorar, na história de Rorschach, os principais elementos que caracterizariam os seus sendeiro inconsciente e sendeiro consciente. Ambos se teriam desencadeado, finalmente, na abordagem direta ao problema básico e, por isso, Rorschach o resolveu aparentemente tão rápido, elaborando o seu famoso método. Neste trabalho, relacionar-se-á, apenas resumidamente, alguns elementos destacados por Ellenberger e que permitem estabelecer relações entre os estudos desenvolvidos sobre as seitas suíças e o referido método.

Rorschach tinha, segundo seu biógrafo, consciência da importância de suas idéias, embora só falasse sobre as mesmas quando já absolutamente seguro de que mereceria atenção. Com relação ao seu próprio itinerário religioso, poder-se-ia supor que ele "sentia um profundo respeito diante dos enigmas do Universo, da vida e do homem" (Ellenberger, 1954/1967, p. 48). Nesse sentido, teria sido uma pessoa religiosa, embora aparentemente não tivesse dado muita atenção à religião convencional e suas práticas. "Como certos filósofos do Romantismo alemão, imaginava uma corrente espiritual fluindo através dos séculos e expressando-se de modo múltiplo na vida 
dos povos e dos indivíduos humanos" (p. 48). Enquanto estudioso, teria ele uma preocupação em achar uma chave para decifrar e compreender todas essas múltiplas formas de manifestação e, em sua opinião, esta seria possível de ser encontrada justamente no âmbito da fantasia criadora. Ao final de sua vida, teria acreditado encontrar a solução definitiva para tais problemas, que teria exposto, segundo seu biógrafo, de forma bastante incompleta, na sua obra mais importante, justamente o seu Psicodiagnóstico. A sua morte prematura o teria impedido de divulgar todas as idéias que já nutria a respeito do assunto. Essas afirmações de Ellenberger podem também ser conferidas no seguinte trecho do artigo necrológico escrito por sua esposa, Olga Rorschach (1943/1967, pp. 95 e 96):

Considerava seu Psicodiagnóstico como a chave do conhecimento do homem e de suas potencialidades e para a compreensão da cultura, esta obra do espírito humano. Vislumbrava dilatadas perspectivas para seu método e via numa futura ampliação do mesmo a possibilidade de fundamentar "O vinculativo" (uma espécie de síntese), o geral-humano. Raramente falava disso. Porém, não considerava o Psicodiagnóstico como algo definitivamente cristalizado, mas apenas um começo; considerava-o in statu nascendi em fluência, como um buscar a firmeza. Esperava colaboradores, continuadores de sua obra. Em sua modéstia, não se atrevia a expressar esse desejo. Sua obra, para ele, estava já articulada. Em sua constante atividade criadora interior, havia avançado até muito mais do que havia deixado exposto nela. Dava-se conta perfeitamente de que seu método carecia de base teórica, e daí sua insistência na "fixação provisoriamente necessária e inimpugnável" da nomenclatura e da formação de conceitos na primeira edição. Preocupava-o muito a possibilidade de que seu método se popularizasse demasiado, pois via nisso um rebaixamento do mesmo ao nível dos adivinhos e dos leitores de cartas. Inquietava-o já muito a tendência de G. Römer (o qual, por outra parte, em que pese suas afirmações, não foi jamais seu colaborador) de desviar seu método para outros rumos. Não via nisso um desenvolvimento ulterior, mas, sim, um desvio e fragmentação provocadores de malentendidos. Três dias antes de sua morte, falava assim disso, e a sua preocupação o fazia sofrer.

Infelizmente, nem tudo que Rorschach já havia elaborado sobre sua obra, além do que ficou exposto no seu Psicodiagnóstico, foi possível resgatar, a despeito de todos os esforços realizados nesse sentido por alguns de seus contemporâneos, como testemunham as Obras Menores e Inéditas, organizada por Bash (1964/1967).

\section{Principais influências e bases teóricas do método}

Pode-se dizer que o núcleo teórico fundamental do método de Rorschach já se encontrava presente no seu trabalho de doutoramento - Reflexhalluzinationen und Verwandte Erscheinungen - cuja versão espanhola encontra-se nas Obras Menores Inéditas, já mencionada anteriormente. Por outro lado, conforme o próprio Rorschach (1912/1967c, pp. 110 e 111) deixa claro logo no início desse trabalho, a inspiração para o mesmo veio de um sonho, assim descrito:

Durante meu primeiro semestre de clínica, presenciei, pela primeira vez, uma autopsia e a estive observando com a proverbial e respeitosa atenção de um jovem estudante. 
A dissecação do cérebro me interessou particularmente e a ela destinei toda classe de reflexões sobre a situação e delimitação da alma. O cadáver era de um apoplético e o cérebro foi cortado em sessões transversais. Na noite seguinte, tive um sonho, durante o qual senti que meu próprio cérebro estava sendo cortado da mesma forma. Um corte depois do outro iam desprendendo-se da massa dos hemisférios, e caíam adiante, exatamente como havia se sucedido na autopsia. Tais sensações corporais (não disponho de outra expressão mais precisa) eram muito claras e a recordação de tal vivência onírica permanece ainda bastante viva em mim, possui o aspecto sensorial das percepções vividas, débil, porém claro.

A partir desse sonho, colocaram-se algumas questões que são retomadas em seu trabalho sobre as alucinações reflexas:

Como são possíveis que, em sonhos, se tenha percepções de fatos fisiológicos? Ressalta que a sensação dos cortes verificados no cérebro tinha sido muito clara e permanecia, anos depois, ainda fresca e viva em sua recordação;

Como seria possível que uma série de imagens óticas pudessem "traduzir-se" em imagens cinestésicas, e serem vividas como tais?

Elaborando essas questões, Rorschach tentou compreender o fenômeno das alucinações reflexas, cujos mecanismos seriam assim explicados:

- O ser humano dispõe de uma quantidade de imagens muito mais ampla do que a que ele experimenta rotineiramente, em sua vida cotidiana. Essa idéia pode ser reencontrada também, mais tarde, no Capítulo IV de seu
Psicodiagnóstico, no seguinte trecho:

O aparelho de vivência como o qual o indivíduo experimenta é um sistema muito mais amplo do que o aparelho com o qual o indivíduo vive. Para experimentar, o indivíduo possui uma série de registros dos quais ele costuma utilizar, em suas ações da vida, apenas alguns e a tal ponto que, freqüentemente, recai na estereotipia (Rorschach, 1921/1974, p. 91).

- Haveria, junto ao enlace natural entre as percepções isoladas por meio de associações, um caminho muito mais direto através do sistema cinestésico. Assim, por meio dos fenômenos sincinéticos, as percepções óticas seriam fixadas diretamente por baixo do umbral da consciência idiocineticamente. Essas percepções seriam, posteriormente, revivenciadas conscientemente como cinestésicas ou, ainda, re-traduzidas inconscientemente em impressões óticas. Esse mesmo princípio teria sido também, mais tarde, aplicado na elaboração do teste de Rorschach, cujas lâminas poderiam ser consideradas uma espécie de espelho, no qual os estímulos óticos ativariam imagens cinestésicas que seriam, por sua vez, projetadas sobre as manchas de tinta e percebidas como pareidolias.

Ellenberger (1954/1967) chama a atenção para a originalidade de Rorschach que, ao invés de procurar interpretar o seu sonho, procurou esclarecer seu mecanismo, retomando, oito anos mais tarde, essas mesmas questões. Entretanto, não deixa de considerar esse sonho como um dos elementos importantíssimos do seu sendeiro inconsciente, afirmando que esse mesmo sonho constitui, sem dúvida, o núcleo de seu trabalho acerca das alucinações reflexas, e, com isso, também do próprio
O aparelho de vivência como o qual o indivíduo experimenta é um sistema muito mais amplo do que o aparelho com o qual o indivíduo vive. 
Psicodiagnóstico. Sobre tal aspecto, é bastante interessante o modo como Miralles (1967) interpreta o sonho de Rorschach e respectivas relações com sua obra e personalidade:

Na época em que teve esse sonho, Rorschach ainda não pensava em seu Psicodiagnóstico. Seus primeiros experimentos com manchas de tinta datam de 1911, e os abandonou para ocupar-se da psicanálise. O sonho data de 1904. Há aqui como que um descobrimento que dá lugar a uma técnica projetiva e a toda uma teoria (inconclusa) acerca da psique humana, tendo como ponto de partida uma imagem íntima, uma visão interior animada pela preocupação acerca dos problemas da vida e da morte, do mais além, das relações entre corpo e alma. Assim como os cortes do cérebro vistos na autopsia representavam para Roschach a estrutura morta onde havia habitado o psíquico, as lâminas de seu teste haveriam de voltar a representar uma ressurreição da matéria inanimada, das manchas de tinta, da superfície de cartolina, mediante a projeção nelas do psíquico, mediante sua animação por um pneuma, um sopro vital insuflado. Não podemos deixar de levar em conta que o sonho mesmo implica uma identificação do próprio Rorschach com o cadáver contemplado na sala de autopsias. Uma vontade de ressurreição, uma negação da morte, um desejo de sobrevivência parecem, pois, fazerse aqui presentes, nos inícios da obra rorschachiana (pp. 9 e 10).

Ainda em seu trabalho sobre as alucinações reflexas, Rorschach (1967c) procurou combinar as contribuições do filósofo norueguês Mourly Vould, que se havia ocupado durante mais de 25 anos da psicofisiologia dos sonhos, com as contribuições psicanalíticas de Freud. De tais contribuições, ressaltou:

- As percepções cinestésicas, que constituem a parte essencial do material onírico, constituem também uma parte essencial da personalidade, e, no estado de vigília, achamse reprimidas, voltando a surgir na consciência durante o sonho.

Percepções e movimentos cinestésicos são antagônicos, tanto que, quando se acorda, é possível recordar o que se sonhou desde que se permaneça imóvel, mas, quando se começa a movimentar, as recordações dos sonhos se vão. Da mesma maneira, as representações cinestésicas seriam favorecidas pela inibição motora.

Quanto maior a inibição dos movimentos musculares, mais vivas se tornam as imagens cinestésicas. Essa tese foi demonstrada por Mourly Vould numa série de experimentos com sujeitos voluntários, enquanto dormiam. Quando obrigados a permanecer imóveis, durante o sono, mais tinham sonhos em que se registravam movimentos humanos.

Nos sonhos experimentais, os sujeitos viviam as imagens cinestésicas como movimentos próprios ou projetados em outras pessoas ou seres parahumanos. Muito mais raramente, projetavam tais movimentos em objetos ou figuras abstratas.

Os chamados sonhos cinestésicos abarcam uma gama de representações, desde movimentos sumamente vivazes até aqueles excessivamente lentos ou mesmo de postura estática. Estas últimas foram consideradas por Mourly Vold como movimentos potenciais reprimidos. 
Uma leitura atenta do Capítulo IV do Psicodiagnóstico, onde Rorschach trata das respostas de movimento (K), permite compreender o quanto este último deve a Mourly Vold. Porém, ao mesmo tempo, fica muito claro o quanto foi hábil para incluir aquelas idéias apontadas acima em um conjunto muito mais amplo, integrando-os com outras, muitas delas da psicanálise, de Freud e/ou de Jung. A genialidade de Rorschach lhe teria possibilitado ver, muito além dali onde outros normalmente veriam apenas duas teorias contrapostas (uma proveniente e adepta da psicofisiologia, e outra, decorrente do estudo do insconsciente), possibilidades de complementaridade. Audaciosamente, ele aproveitou ambas. Em sua concepção, portanto, os fatores cinestésicos assinalados por Mourly Vold constituiriam o material sensorial, sem o qual não se pode sonhar. Esse material seria, então, configurado pelos fatores dinâmicos assinalados por Freud. Essa síntese fica, aqui, assim explicitada, em seu trabalho Alucinação Reflexa e Simbolismo (Rorschach, 1912/1967a, p. 165):

Uma síntese das concepções de Freud e de Mourly Vold acerca dos sonhos poderia resumir-se, provavelmente, do seguinte modo: em última instância, o que decide acerca da forma adotada pelo sonho não se trata de desejos, temores, complexos, ou seja, de fatores psíquicos; entre os meios de expressão, o papel mais importante corresponde aos símbolos, que a todo momento estão à disposição do pensamento onírico. Com freqüência, são postos em ação por estímulos somáticos, surgindo, assim, o que Mourly Vold qualifica de "momentos". Tornar-se-iam manifestos devido a uma de suas qualidades, sobretudo se se trata de conteúdos de movimento e de uma semelhança ótica, alcançam o nível de excitação sensorial, como conseqüência de qualquer qualidade análoga ou idêntica correspondente a uma sensação real, e faz, então, com que as outras qualidades conectadas com ela alcancem o nível de percepção sensorial. Os "momentos" de Mourly Vold constituem parte do material de construção, os símbolos são os obreiros, os complexos, os mestres de obras e capatazes, a psique onírica, o arquiteto do edifício que denominamos sonho.

Pode-se, compreender, a partir dessa síntese, que o símbolo surgiria exatamente ali onde entram em contato o material cinestésico, explicado por Mourly Vold, e a dinâmica inconsciente, explicada por Freud, e quanto mais fortemente se tenha gravado uma representação de índole complexa no material representado pela sensações cinestésicas, tanto mais fácil será que ele se projete, como símbolo onírico, como alucinação reflexa em uma psicose ou afirma Ellenberger (1954/1967) - como resposta de movimento original no teste de Rorschach. Para Rorschach, não só o sonho levaria aos fenômenos cinestésicos mas também toda modalidade de atividade assimiladora e criadora. A isso, mais tarde, atribuiu o nome de introversão, conceito inspirado em Jung, mas que Rorschach fez questão de ressaltar a sua não-equivalência à tipologia estabelecida por aquele ao referirse à polaridade introvertido-extravertido.

\section{A subjacente concepção de personalidade}

No quarto capítulo do Psicodiagnóstico, Rorschach (1921/1974) explica detalhadamente o que entende pela bipolaridade, que ocupa um papel central em sua teoria psicológica, e a que chamou de introversivo-extratensivo, e suas relações 
com as respostas de movimento e com as respostas cromáticas. Descreve as relações que os termos estabelecem com aquela tipologia dada por Jung, mas também demonstra sua originalidade e independência de pensamento ao integrar mutuamente as percepções cinestésicas, a energia criadora e a introversão, por um lado, e, por outro, as percepções cromáticas, a inteligência reprodutora e a extraversão. Sendo assim, dá um sentido diferente àquela tipologia dada por Jung, especialmente nos seguintes aspectos:

Ao contrário do que teria suposto Jung, Rorschach não atribui aos dois termos da polaridade a idéia de dois tipos constitucionais que se excluem mutuamente, mas, muito mais, duas funções psicológicas universalmente dadas, sem estarem, necessariamente, contrapostas entre si. Tanto isso é verdade, que vai introduzir os termos ambigüal, coartado e coartativo para referir-se a modos possíveis de combinação de maior presença ou ausência de uma ou ambas as funções descritas - introversivo e extratensivo.

Como funções psicológicas, ambas são afetivas e ativas, sendo possível, em cada momento, voltar-se mais a uma ou a outra. São ambas necessárias ao indivíduo e à humanidade, sendo a introversão a base da cultura e a extratensão a base da civilização.

As relações mútuas entre ambas as funções, que serão encontradas em todos os sujeitos, podem ser constatadas pelo seu Psicodiagnóstico, sendo que, ao grau em que estarão distribuídas, assim como à sua proporção recíproca, é atribuído o termo tipo de vivência.
Ainda no Capítulo IV do seu Psicodiagnóstico, Rorschach (1921/1974) descreve várias possibilidades de relações entre ambas as funções: a de introversão função identificada pelas respostas de movimento (cinestésicas, portanto), - e a de extraversão - função dada pelas respostas de cor (cromáticas, portanto). Essas várias possibilidades são assim descritas, no referido capítulo:

Introvertido, onde predominam as respostas de movimento - tipo $\mathrm{K}$, com as seguintes características:

Inteligência mais diferenciada, mais produtividade própria, vida mais orientada para o interior, afetividade mais estabilizada, menor capacidade de adaptação à realidade, contato mais intensivo que extensivo, mobilidade comedida, mais estável, comportamento desajeitado, inabilidade (p. 81).

Extratensivo, onde predominam as respostas de cor - tipo $\mathrm{C}$, registrando-se, portanto, as seguintes características:

Inteligência mais estereotipada, mais reprodutividade, vida mais orientada para o exterior, afetividade lábil, maior capacidade de adaptação à realidade, contato mais extensivo que intensivo, mobilidade excitável, lábil, jeito, habilidade (p. 81).

Coartado, onde não se encontram nem respostas de movimento e nem respostas de cor - OK : 0C. "Deve tratar-se, pois, de casos nos quais os momentos introversivos com os extratensivos acham-se reduzidos ao mínimo" (p. 87), sendo comum apenas em alguns casos normais isolados, em alguns meticulosos, alguns depressivos e, ainda, vez ou outra, em dementes, paranóides 
indolentes, melancólicos e dementes arterioscleróticos com perturbação depressiva. Seriam pessoas que estariam sempre preocupadas com o seu próprio $E u$, num constante e torturante autocontrole.

- Coartativo, onde a proporção entre K e C é mínima - 1K: 1C, registrando-se uma tendência à coartação nos moldes descritos anteriormente.

Ambigüal, onde se agrupam os mais variados tipos, registrando-se uma proporção alargada tanto de respostas movimentos - K, como de respostas cromáticas - C. Segundo Rorschach (p. 88),

Aqui, então, deveria estar reunido um elevado grau de momentos introversivos com um grau igualmente elevado de momentos extratensivos. Os mais variados quadros clínicos encontram-se aqui reunidos e não seria fácil reuni-los sob uma designação típica que pudesse identificar algo.

Dentre as várias possibilidades relacionadas acima, Rorschach não deixou de registrar que haveria, naturalmente, todo gênero de transições e discute-as detalhadamente, tomando também, como parâmetros, todos os demais elementos do teste, estabelecendo relações tanto com o eixo das localizações como com o dos conteúdos e, ainda, com os demais elementos determinantes, em especial, a qualidade das respostas formais. O conceito de tipo de vivência constitui-se como que no núcleo do Psicodiagnóstico. Conforme o acentua Ellenberger (1954/ 1967), à época em que Rorschach o inventou, tratava-se de um conceito absolutamente novo e que não se assemelhava a nenhuma outra idéia então já apresentada em toda a Psicologia Ocidental. O biógrafo considera que o conceito que mais se aproximaria deste seria aquele dado pela Psicologia hindu, ou seja, o conceito de Karma, mas este tomado em sua acepção original, antes de ter sido posto em relação com o conceito de samsara, este último significando a cadeia sucessiva de reencarnações. Karma, em seu sentido primeiro, seria, então,

... o incessante devir e agir de um invisível núcleo da personalidade que, mesmo inconsciente, é formado continuamente por nossos atos e pensamentos conscientes e que, por sua vez, contribui, por sua parte, a determiná-los: trata-se do indissolúvel vínculo existente entre um ser vivo e todos os seus atos anteriores (p. 59).

De fato, como pode ser constatado no Capítulo IV do seu Psicodiagnóstico, Rorschach (1921/1974) caracteriza o tipo de vivência como sendo a mais íntima e essencial capacidade de ressonância com as experiências da vida, ao mesmo tempo em que o relaciona também com a elaboração inconsciente dessas novas experiências. Estabelece conexões entre o tipo de vivência e praticamente todos os demais aspectos da vida, partindo do princípio de que o mesmo revelaria a extensão do aparelho psíquico com o qual o indivíduo poderia viver. Esclarece que o tipo de vivência de um indivíduo não corresponde, necessariamente, ao psicograma geral dado pelo teste: "Ele apenas indica como o indivíduo experimenta, não como ele vive ou o que ele ambiciona" (p. 91). Admite, portanto, discrepâncias entre o tipo de vivência e a vida, mas que só poderiam ser explicados

... pelo fato de a energia vital, o grau de energia ativa, atuante em determinado momento, a vontade, a libido, ou seja qual
... o incessante devir e agir de um invisível núcleo da personalidade que, mesmo inconsciente, é formado continuamente por nossos atos e pensamentos conscientes e que, por sua vez, contribui, por sua parte, a determiná-los: trata-se do indissolúvel vínculo existente entre um ser vivo e todos os seus atos anteriores (p. 59). 
for o nome que se possa dar a isso, esteja dirigida apenas para uma parte das possibilidades de vivência. Somente o impulso transforma os "momentos" disposicionais em tendências ativas (p. 91).

Assim, ainda no Capítulo IV, após esclarecer o conceito em pauta, Rorschach apresenta vários elementos da relação entre o tipo de vivência de um indivíduo e demais aspectos da vida: a) o tipo de vivência e a vida; b) o tipo de vivência e os componentes da inteligência; c) o tipo de vivência e as perturbações; d) as variações temporárias do tipo de vivência habitual do indivíduo; e) as transformações do tipo de vivência no transcurso da vida; f) estudos comparativos sobre o tipo de vivência; g) a afetividade e o caráter; e) a imaginação; h) tipos de vivência e tipo de representação; i) o tipo de vivência e o tipo de alucinação; j) o tipo de vivência e os talentos; I) tipo de vivência, talento e impulso; m) tipo de vivência, caráter e talentos; n) tipo de vivência e enfermidade; o) o problema da evolução do tipo de vivência.

Sobre o último aspecto relacionado acima, Rorschach acreditava que, no transcurso da vida humana, o tipo de vivência evoluiria lenta, constante e autonomamente. Embora afirmasse não ter, ainda, elementos que pudessem levar ao reconhecimento da gênese do tipo de vivência, visualizava alguns pontos do que chamou "dessa vasta rede de problemas causais" (Rorschach, 1921/1974, p. 124), apontando que a finalidade ótima do desenvolvimento humano seria a seguinte:

O mais intenso desenvolvimento possível do pensamento disciplinado, da função lógica, mas não a ponto de alcançar a extrema coartação dos momentos introversivos e extratensivos ou de sacrificar a própria capacidade de vivenciar (meticulosos, intelectualistas puros);

- A mais intensa capacidade de introversão possível, mas não a ponto de usurpar o pensamento disciplinado (sonhadores), e não a ponto de destruir a capacidade de adaptação afetiva (abstratos, estranhos ao mundo);

- A mais intensa capacidade de extratensão possível, mas não a ponto de volatilizar o pensamento disciplinado (estouvados), e não a ponto de reprimir a capacidade de introversão (puros homens de negócios) (p. 124).

$\mathrm{Na}$ verdade, um grande projeto de Rorschach seria o de realizar aplicações do teste em diferentes estágios do desenvolvimento humano, de modo a obter um gráfico que seguisse as respectivas transformações desde a infância até a senectude, no qual se verificasse a curva vital de cada indivíduo. Perguntava-se, por exemplo, que resultados seriam obtidos se tais curvas fossem comparadas entre pessoas pertencentes a uma mesma família ou profissão e suas respectivas comparações com as curvas vitais corrrespondentes a pessoas de outras raças ou nações. Conta Ellenberger (1954/1967) que ele chegou a começar investigações comparadas de sujeitos do cantão de Berna e do cantão de Appenzell, tendo manifestado o desejo de realizar também investigações em negros africanos e em indígenas congoleses. Teria, ainda, desejado realizar um estudo sistemático das pinturas procedentes de séculos passados, como também uma análise dos movimentos e das cores que nelas se registravam, de modo a reconstruir a mentalidade da época correspondente. 
Um outro conceito importante em Rorschach é aquele introduzido mesmo antes de seu Psicodiagnóstico, quando trabalhava intensamente no estudo das seitas suíças, mas que é retomado posteriormente nos pressupostos teóricos e nas análises dos resultados obtidos com os experimentos realizados com as manchas de tinta. Tratase do que ele chamou, inicialmente, de fonction du réel (termo introduzido na França por Pierre Janet) - função do real. Posteriormente, entretanto, especialmente no Capítulo IV do Psicodiagnóstico, quando se refere aos componentes da inteligência, usa a expressão função lógica para referir-se às mesmas funções de adaptação à realidade e/ou de controle dos impulsos e desejos inconscientes. Procura, então, demonstrar, ao relatar seus experimentos acerca das tendências de influenciabilidade dos fatores do teste uns sobre os outros, como a função do real pode atuar como inibidora tanto de cinestesias como da expressão da afetividade ou motilidade.

No teste, os fatores mais relacionados à chamada função lógica seriam: capacidade de atenção constante e ativa (dadas pelas respostas de boa forma - $\mathrm{F}+$, e pela sucessão, rígida ou ordenada); a acuidade de percepção e dos processos associativos durante o trabalho de assimilação (também dadas pelas respostas de boa forma - $\mathrm{F}+$ ); a capacidade de dosar e de disciplinar a função lógica (sucessão e tipos de apreensão); capacidade de formação de atitudes associativas estereotipadas (A\%). Todos esses fatores são susceptíveis de aumento quando se estimula o examinando para tanto, dirigindo sua atenção para os mesmos. Entretanto, um aumento do rendimento conscientemente desejado de tais fatores será acompanhando de uma redução de outras disposições, tais como: energia de atividade associativa (dadas pelas respostas globais - G); liberação de associações das atitudes associativas estereotipadas (ou seja, redução de $\mathrm{A} \%)$; capacidade de formar associações originais (respostas globais originais e de boa forma - G+); capacidade de criação interior (K). Em conclusão: um aumento de rendimento conscientemente desejado das funções gerais, enumeradas no primeiro grupo, traria como conseqüência um enfraquecimento significativo do rendimento das disposições diferenciais, enumeradas no segundo grupo. Ao contrário, um aumento consciente e desejado de rendimento das funções citadas no segundo grupo não causaria diminuição das funções enumeradas no primeiro, não obstante existir uma tendência nessa direção.

Rorschach (1921/1974) apresenta, então, as suas conclusões de que as capacidades do primeiro grupo, ou seja, as mais relacionadas à função lógica ou adaptativa, são passíveis de serem adquiridas, enquanto as do segundo grupo seriam dons. Ainda segundo ele, a afetividade não poderia ser incluída em nenhum dos dois grupos, pois escaparia a qualquer agrupamento semelhante. Citando Bleuler: "A atenção é uma forma de expressão da afetividade" (p. 73), afirma que a afetividade permaneceria estabilizada no caso de aumento do rendimento dos elementos relacionados no primeiro grupo. Atenção concentrada significaria afetividade estabilizada. Entretanto, com o aumento do rendimento dos componentes relacionados no segundo grupo, a afetividade, geralmente, seria mais lábil.

A relação estabelecida por Rorschach entre a função do real e as demais funções psíquicas por ele estudadas e investigadas com o teste, entendidas no seu dinamismo intrínseco, 
permitem compreender melhor as suas idéias acerca da finalidade ótima do desenvolvimento humano, apresentadas anteriormente. Tais idéias já estavam presentes desde o seu estudo anterior, realizado com o estudo e investigação dos casos Johannes Binggeli e Anton Unternährer, os quais foram por ele diagnosticados, respectivamente, como um caso de neurose e um caso de esquizofrenia (Rorschach, 1927/ 1967b e 1917/1967d).

Infelizmente, Rorschach veio a falecer em abril de 1922, apenas nove meses depois de ter, finalmente, publicado o seu Psicodiagnóstico. Conforme diz seu biógrafo, Rorschach sucumbiu e levou consigo grande parte de seu segredo. A afirmação procede, pois sabe-se que ele já se ocupava de vários planos para melhorar e continuar desenvolvendo seu método, para o qual desejava buscar fundamentos cada vez mais assentados na fenomenologia. Naturalmente mobilizado pela genialidade de Rorschach e pelo grande sentimento de perda que significou a morte do grande amigo, Ellenberger (1954/1967) assim imagina como teria sido se Rorschach tivesse sobrevivido à sua enfermidade:

Não cabe dúvidas de que, uma vez superadas as dificuldades iniciais, seu renome científico teria aumentado à medida que seu trabalho progredisse. Como primeiro em seu gênero, seu livro sobre seitas suíças poderia ter feito época no setor da psicologia das religiões. Alguns anos mais tarde apareceria a segunda edição do Psicodiagnóstico, enriquecida pelas contribuições da psicologia da configuração, a fenomenologia e os novos testes. A evolução de Rorschach, no fundo, achavase, por completo, enraizada na fenomenologia. Conhecia pessoalmente a Eugène Minkowski e a Ludwig Binswanger, cujas primeiras contribuições à fenomenologia psiquiátrica apareceram alguns anos depois da morte de Rorschach. Com seu assombroso polifacetismo e sua capacidade de síntese, talvez nos tivesse proporcionado uma nova Antropologia e uma psiquiatria novas, uma síntese de Psicologia experimental, psicoanálise e fenomenologia (p. 70).

O zeloso biógrafo relata também que, em 26 e 27 de junho de 1943, a Sociedade Suíça de Psiquiatria celebrava um congresso dedicado ao método de Rorschach e sua aplicação à psiquiatria, justamente em Münsterlingen, que havia se convertido em um centro de investigação do teste, combinando-se estudos estatísticos gerais com outros fenomenológicos mais especializados. E, nesse mesmo cantão da Suíça, comemorava-se, poucos dias antes, os 70 anos de Ludwg Binswanger com uma homenagem deliberadamente científica, onde cada um dos assistentes teria previamente recebido um protocolo do método de Rorschach com o objetivo de estudá-lo antes da festividade. Por ocasião, discutiu-se a valorização fenomenologicamente orientada, por mostrar-se "muito mais fecunda que o método corrente, e vários dos participantes tiveram a impressão de que era possível reativar o fio que parecia ter-se interrompido com o falecimento do autor" (p. 66). 


\section{Marta Helena de Freitas}

Doutora em Psicologia pela

Universidade de Brasília e professora-adjunta dos

Programas de Pós-

Graduação em Gerontologia

e Psicologia e de Graduação em Psicologia da

Universidade Católica de Brasília

Rua 3/4 Sul, Lote 7/10, Bl.

"B", apto 804 - 72022-900

Águas Claras - DF

E-mail:mhelena@ucb.br

ANZIEU, D. Os Métodos Projetivos. (M. L. do Eirado Silva, trad.) Rio de Janeiro: Campus, (1961) 1979.

BASH, K. W. (recop.) Hermann Rorschach: Obras Menores e Inéditas. (A. G. Miralles, trad.). Madrid / Espanha: Morata (1964) 1967.

Tabula Undecima - Seu Smaragdina. In Bash, K. W. (recop.). Hermann Rorschach: Obras Menores e Inéditas. (A. G. Miralles, trad.). Madrid / Espanha: Morata, (1964) 1967b.

ELLENBERGER, H. Vida y Obra de Hermann Rorschach (18841922). In Bash, K. W. (recop.) Hermann Rorschach: Obras Menores e Inéditas. (A. G. Miralles, trad.). Madrid / Espanha: Morata (1954) 1967, pp.25-103.

KLOPFER, B. \& KELLY, D. Técnica del Psicodiagnóstico de Rorschach. (D. Carnelli, trad.). Buenos Aires: Paidós (1942) 1974.

JUNG, C. G. A Vida Simbólica. (Araceli Elman, trad.). Petrópolis: Vozes (1981) 1988

MIRALLES, A. G. Prólogo a la Versión Española. In Bash, K. W. (recop.). Hermann Rorschach: Obras Menores e Inéditas. (A. G. Miralles, trad.). Madrid / Espanha: Morata (1964) 1967, pp. 7-11.

MORGENTHALER, W. La Lucha por la Aparición del "Psicodiagnostico". In Bash, K. W. (recop.). Hermann Rorschach: Obras Menores e Inéditas. (A. G. Miralles, trad.). Madrid / Espanha: Morata (1954 e ligeiramente abreviado para nova publicação em 1964)1967, pp. 97-103.

Recuerdos de Hermann Rorschach. In Bash, K. W. (recop.). Hermann Rorschach: Obras Menores e Inéditas. (A. G. Miralles, trad.). Madrid / Espanha: Morata (1964) 1967, pp. 97-103.
RORSCHACH, H. Alucinación Refleja y Simbolismo. In Bash, K. W. (recop.). Hermann Rorschach: Obras Menores e Inéditas. (A. G. Miralles, trad.). Madrid / Espanha: Morata (912) 1967a, pp. 248-289.

Los Fundadores de Sectas Suizos (BinggeliUnternährer). In Bash, K. W. (recop.). Hermann Rorschach: Obras Menores e Inéditas. (A. G. Miralles, trad.). Madrid / Espanha: Morata (1927) 1967b.

Sobre las "Alucinaciones Reflejas" y otras Manifestaciones Analogas. In Bash, K. W. (recop.). Hermann Rorschach: Obras Menores e Inéditas. (A. G. Miralles, trad.). Madrid / Espanha: Morata (1912) 1967c, pp. 107-152.

. Sobre las Sectas Suizas y sus Fundadores. In Bash, K. W. (recop.). Hermann Rorschach: Obras Menores e Inéditas. (A. G. Miralles, trad.). Madrid / Espanha: Morata (1917) 1967d, pp. 201-207.

Psicodiagnóstico. (M. S. V. Amaral, trad.). São Paulo: Mestre Jou (1921) 1974

Sobre la Vida y el Modo de Ser de Hermann Rorschach. In Bash, K. W. (recop.). Hermann Rorschach: Obras Menores e Inéditas. (A. G. Miralles, trad.). Madrid / Espanha: Morata (1943) 1967 pp. 89-96.

SEEBER, V. K. Justinus Kerner - Biographie. Literarische Landschaft Heilbronn, DutchEss, Dutch Eletronic Subject Service, http:/www.dla-marbach.de/dla-marbach.html (1975) 1999. 